Adopting aspects of the Dutch system may be problematic, Marcoux said. For example, Canada's low population density makes it difficult to provide timely services in remote areas.

There's also a difference in where people die: $66 \%$ of Canadians die in hospital compared with $40 \%$ of the Dutch. This may affect delivery of MAiD. And many Canadians don't enjoy long-standing relationships with their physician, like Dutch people typically have. "It's hard to make an assessment when you don't know the patient and their values," said Marcoux.
"Particularly in cases when intervention is urgent."

"The challenge will be to see the quality of MAiD you can reach," said Kimsma. "You will have to find your own way." - Barbara Sibbald, CMAJ

CMAJ 2016. DOI:10.1503/cmaj.109-5342

\title{
Most contributors to major US cancer guidelines have financial conflicts
}

$\mathrm{O}$ $f$ the 125 contributors to four major clinical guidelines for cancer treatment in the United States, $86 \%$ had at least one financial competing interest with industry, according to a recent study. This is of concern because doctors rely on these guidelines to make decisions about cancer treatments for their patients, and financial ties have the potential to bias a physician toward recommending a specific company's product, according to study coauthor Stacie Dusetzina, an assistant professor in the Division of Pharmaceutical Outcomes and Policy at the University of North Carolina Eshelman School of Pharmacy.

"If the recommended product is expensive and doesn't have clear evidence of benefiting patients, then it could just be adding more costs to the patient," Dusetzina said in an email to CMAJ. "These costs are referred to as 'financial toxicity' in cancer care in the US, as they can often be very high and a huge burden for patients."

The study, published in JAMA Oncology, found that $84 \%$ of guideline authors received general payments from industry (for things such as consulting, meals and lodging) and $47 \%$ received money for research. The average general payment had a value of US\$10 011; the average research payment was US\$236 066. The study considered financial competing interests in 2014 among contributors to four National Comprehensive Cancer Network (NCCN) guidelines: for lung, breast, prostate and colorectal cancer.

"The NCCN does a good job of managing conflicts of interest overall," said Dusetzina. "I think the most important thing is to be explicit about payments received so that any potential biases are recognized and recommen-

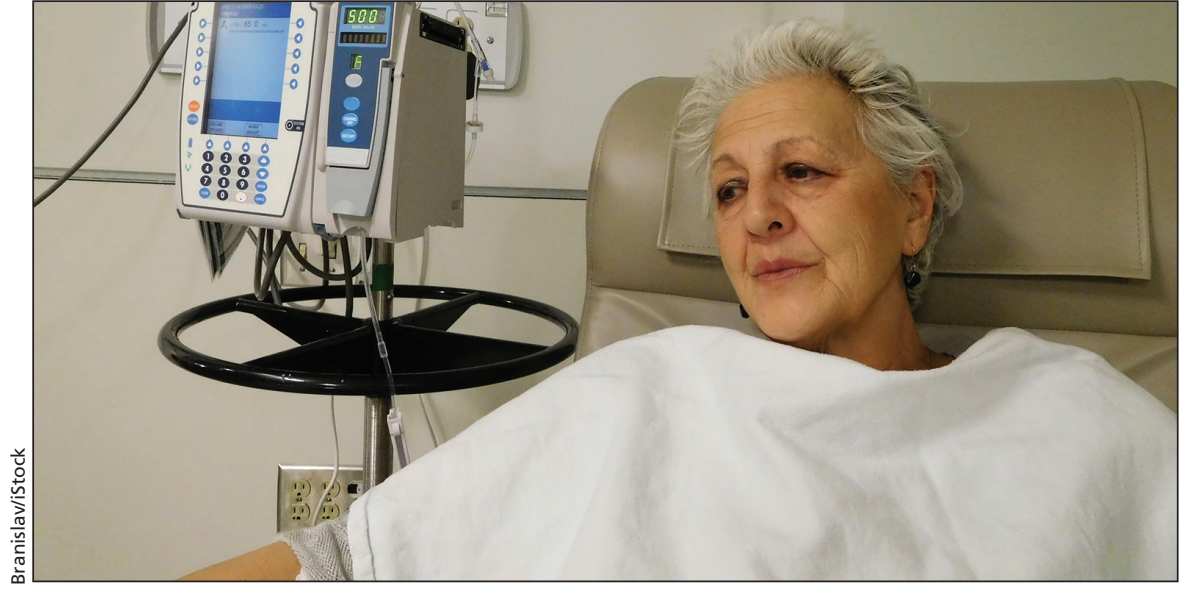

Many doctors rely on clinical guidelines to make decisions about cancer treatments.

dations are considered in light of these potential conflicts."

When contacted by CMAJ for comment, a representative for the National Comprehensive Cancer Network said it was not holding interviews at this time and was preparing a formal public response.

As pharmaceuticals get more and more expensive, clinical guidelines become all the more valuable in guiding treatment decisions, according to Dr. Otis Brawley, chief medical officer of the American Cancer Society. "The issue is that you have people who make money doing the treatments actually deciding what the treatments should be," he said "Unfortunately, these are also the people who are the most expert in outcomes."

The good thing about financial competing interests, however, is that they are easier than ever to monitor in the US, thanks to the 2010 Physician Payments Sunshine Act, a US law that requires drug companies to disclose payments to doctors. According to Brawley, the usual practice on guideline committees is to exclude individuals with major competing interests. Physicians with minor financial ties to industry must still disclose these, but can participate if they believe they can be objective and open-minded.

"The key is you can't avoid them; you need to manage them," Brawley said about financial competing interests.

Of more concern are what Brawley calls emotional competing interests. These occur when a member of a guideline committee absolutely refuses to reconsider his or her opinion on a treatment in light of new evidence, he said. Such stubborn individuals aren't practising evidence-based medicine, he said; they are practising faith-based medicine.

"Those ones are a bigger problem. The guys who are making money know they are making money," he said. "The close-minded individual doesn't realize he or she is prejudiced." - Roger Collier, CMAJ

CMAJ 2016. DOI:10.1503/cmaj.109-5334 